\title{
Estimating Submicron Aerosol Mixing State at the GLOBAl SCALE WITH MACHINE LEARNING AND EARTH SYSTEM MODELING
}

\author{
Zhonghua Zheng \\ Department of Civil and Environmental Engineering \\ University of Illinois at Urbana-Champaign \\ Urbana, IL 61801 \\ zzheng25@illinois.edu \\ Yu Yao \\ Department of Atmospheric Sciences \\ University of Illinois at Urbana-Champaign \\ Urbana, IL 61801 \\ yuyao3@illinois.edu \\ Valentine G. Anantharaj \\ National Center for Computational Sciences \\ Oak Ridge National Laboratory \\ Oak Ridge, TN 37831 \\ anantharajvg@ornl.gov \\ Matthew West \\ Department of Mechanical Science and Engineering \\ University of Illinois at Urbana-Champaign \\ Urbana, IL 61801 \\ mwest@illinois.edu
}

\author{
Jeffrey H. Curtis \\ Department of Mechanical Science and Engineering \\ University of Illinois at Urbana-Champaign \\ Urbana, IL 61801 \\ jcurtis2@illinois.edu
}

Jessica T. Gasparik

Department of Atmospheric Sciences

University of Illinois at Urbana-Champaign

Urbana, IL 61801

jtg4@illinois.edu

\section{Lei Zhao}

Department of Civil and Environmental Engineering

University of Illinois at Urbana-Champaign

Urbana, IL 61801

leizhao@illinois.edu

\author{
Nicole Riemer \\ Department of Atmospheric Sciences \\ University of Illinois at Urbana-Champaign \\ Urbana, IL 61801 \\ nriemer@illinois.edu
}

May 5, 2020

\begin{abstract}
This study integrates machine learning and particle-resolved aerosol simulations to develop emulators that predict sub-micron aerosol mixing state indices from the Earth System Model (ESM) simulations. The emulators predict aerosol mixing state using only ESM bulk aerosol species concentrations, which do not by themselves carry mixing state information. Here we used PartMC as the particle-resolved model and NCAR's CESM as the ESM. We trained emulators for three different mixing state indices for sub-micron aerosol in terms of chemical species abundance $\left(\chi_{\mathrm{a}}\right)$, the mixing of optically absorbing and non-absorbing species $\left(\chi_{\mathrm{o}}\right)$, and the mixing of hygroscopic and non-hygroscopic species $\left(\chi_{\mathrm{h}}\right)$. Our global mixing state maps show that there is considerable spatial and seasonal variability in mixing state indices, ranging between $23 \%$ and $96 \%$ for $\chi_{\mathrm{a}}$, between $49 \%$ and $95 \%$ for $\chi_{\mathrm{o}}$, and between $19 \%$ and $90 \%$ for $\chi_{\mathrm{h}}$, with averages of $76 \%, 75 \%$, and $63 \%$, respectively. High values in one index can be consistent with low values in another index depending on the grouping of species and their relative abundance, meaning that each mixing state index captures different aspects of the population mixing state. Although a direct validation with observational data has not been possible yet, our results are consistent with mixing state index values derived from ambient observations. This work is a prototypical example of using machine learning emulators to add information to ESM simulations.
\end{abstract}




\section{Introduction}

Aerosol particles in the atmosphere are evolving mixtures of different chemical species. The term "aerosol mixing state" is used to describe how different aerosol chemical species are distributed among and within the aerosol particles [1]. As stated by Winkler [2], "the same net composition of an aerosol can be caused by an infinite variety of different internal distributions of the various compounds". An "internally mixed" aerosol refers to the state where the composition of all particles within the population is the same (and equal to the bulk composition of the aerosol), while an "externally mixed" aerosol has all particles of a population consisting of only a single species. In reality, aerosol mixing states are between internal and external mixtures as shown in many observational studies [3, 4, 5, 6, 7]. Aerosol mixing state greatly influences the particles' hygroscopicity [8, 9], their optical properties [10, 11], their cloud condensation nuclei $(\mathrm{CCN})$ activity [12, 13], their ice nucleation potential [14], and the aerosols' lifetime in the atmosphere [15].

To quantify mixing state, Riemer and West [16] introduced a metric, the mixing state index $\chi$, based on diversity measures derived from the information-theoretic (Shannon) entropy of the chemical species distribution among particles, with per-particle mass fractions as the fundamental quantities. The mixing state index $\chi$ varies between $0 \%$ (for completely external mixtures) and $100 \%$ (for completely internal mixtures) for any given aerosol. The metric has been applied to field observations in different environments, e.g., Paris during the MEGAPOLI campaign [4], in Northern California during CARES [17], in central London [18], and in Pittsburgh, PA [5]. It has provided useful to gain insights into the processes that govern diurnal changes in mixing state, and mixing state changes related to air mass origin. It can also be used in a framework for error quantification as shown in Ching et al. [19] for the example of CCN concentration predictions using aerosol models that simplify aerosol mixing state.

The most direct way of predicting aerosol mixing state and its index $\chi$ is to employ a particle-resolved model. This modeling approach allows for tracking the composition of individual particles and therefore $\chi$ can be directly calculated. However, particle-resolved modeling is extremely computationally expensive and thus not practical for use in large-scale models. Alternatively, Hughes et al. [20] developed a method that uses the output of a large ensemble of particleresolved box model simulations combined with machine learning techniques to train a model of the mixing state metric $\chi$. This lower-order model for $\chi$ uses as inputs only variables known to the global climate model of interest (in Hughes et al. [20] it was GEOS-Chem-TOMAS, which uses a sectional aerosol modeling approach assuming an internal mixture within each size bin). The outcomes of this procedure were global maps of $\chi$ based on GEOS-Chem-TOMAS data.

In this work, we revisit the approach by Hughes et al. [20] with the following new contributions. We used the Community Earth System Model (CESM [21, 22]) in conjunction with the Modal Aerosol Module (MAM4 [23]) as a large-scale model that provides the features for the machine learning procedure. We compared and contrasted the spatial distribution and seasonal variation of aerosol mixing state indices at a global scale, where the mixing state index was defined in three different ways (see Section 3): in terms of chemical species abundance, in terms of the mixing of optically absorbing and non-absorbing species, and in terms of the mixing of hygroscopic and non-hygroscopic species. Our workflow is shown in Figure 1 and is composed of three parts: (1) PartMC-MOSAIC [24, 25] simulations to produce training data (see Section 2), (2) machine learning-enabled aerosol mixing state emulation (Section 4), and (3) global aerosol mixing state indices estimation (Section 5).

\section{Ensemble of particle-resolved model scenarios}

To generate the training data, we ran an ensemble of particle-resolved model scenarios using the PartMC-MOSAIC. This section gives an overview of the model and the design of the scenario ensemble.

\subsection{PartMC-MOSAIC model description}

PartMC is a particle-resolved tool to model the aerosol mixing state and its impacts under various meteorological and environmental conditions [24]. In brief, this box model simulates individual aerosol particles within a representative volume of air, including stochastic coagulation, gas- and particle-phase chemistries, particle-phase thermodynamics, and dynamic gas-particle mass transfer. The process of new particle formation was not included in the simulations shown in this paper. The PartMC algorithm has storage cost proportional to the number of particles, computational cost for evaporation/condensation proportional to the number of particles, and computational cost for coagulation proportional to the number of coagulation events. PartMC has been coupled with the state-of-the-art aerosol chemistry model MOSAIC (Model for Simulating Aerosol Interactions and Chemistry [25]) to provide the chemistry modules. MOSAIC consists of four computationally efficient modules: (1) the gas-phase photochemical mechanism CBM-Z [26]; (2) the multicomponent Taylor expansion method (MTEM) for estimating activity coefficients of electrolytes and ions in aqueous solutions [27]; (3) the multicomponent equilibrium solver for aerosols (MESA) for intra-particle solid-liquid partitioning [28]; and (4) the adaptive step time-split Euler method (ASTEM) for dynamic gas-particle partitioning over 
A PREPRINT - MAY 5, 2020

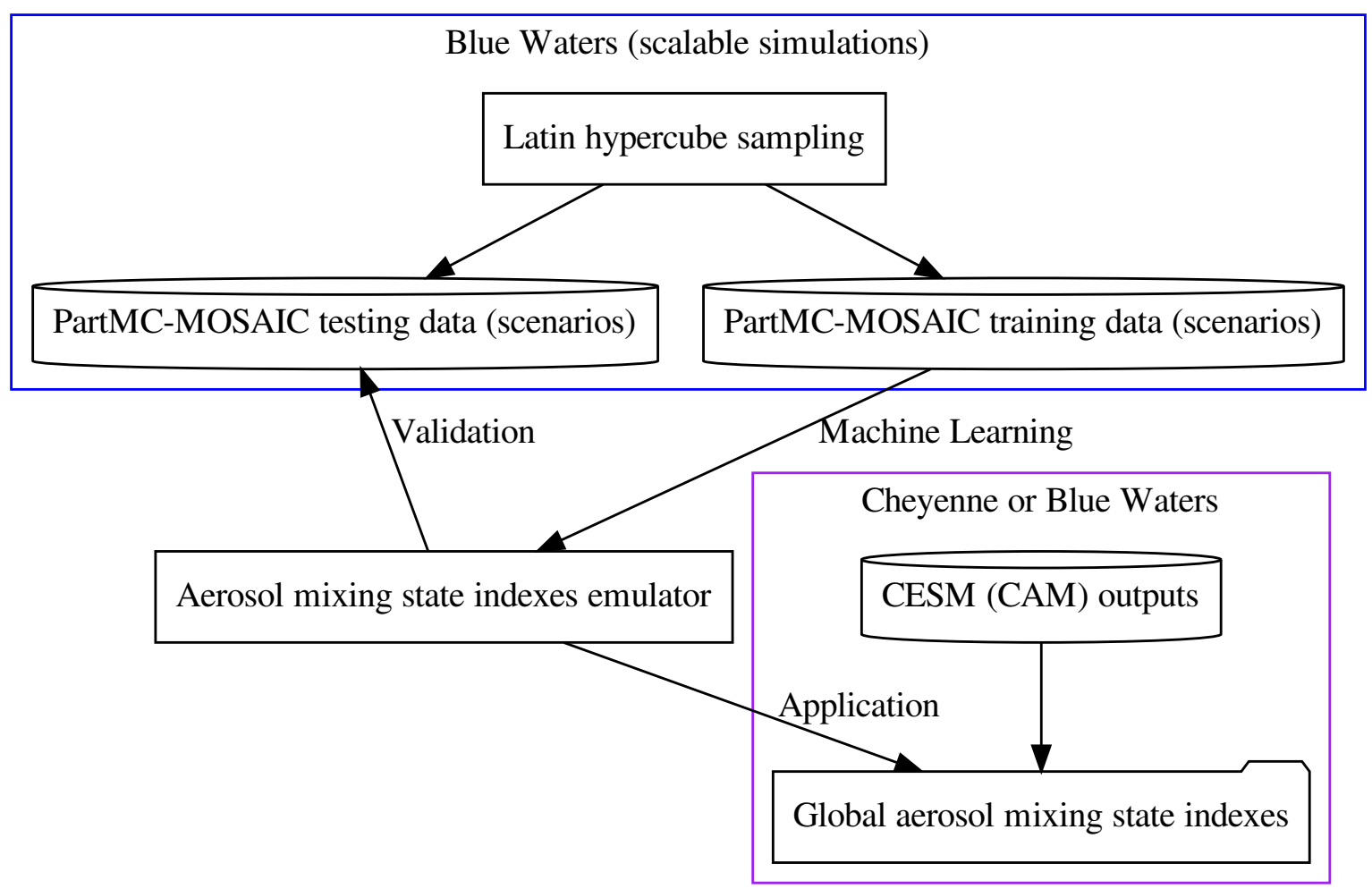

Figure 1: Schematic of the workflow for estimating the mixing state index $\chi$ on a global scale. The simulations were run on the Blue Waters and Cheyenne supercomputers.

size- and composition-resolved aerosol [25]. Secondary organic aerosol from anthropogenic and biogenic precursors is included using the Secondary Organic Aerosol Model (SORGAM) [29]. Overall, MOSAIC treats all locally and globally important gas and aerosol species, including sulfate, nitrate, chloride, carbonate, ammonium, sodium, calcium, primary organic aerosol (POA), secondary organic aerosol (SOA), black carbon (BC), and inert inorganic mass (a surrogate species for mineral dust).

The coupled model system, PartMC-MOSAIC, predicts number, mass, and full composition distributions without a priori assumptions about their evolution, which is suitable for use as a numerical benchmark of mixing state for more approximate models [30, 11, 8]. Here we used PartMC-MOSAIC simulations to provide data for training and testing emulators that predict the mixing state indices on the global scale.

\subsection{Design of training and testing scenarios}

The PartMC-MOSAIC training and testing scenarios provide a large number of particle populations with different mixing states aiming at covering the range of conditions found in different environments around the globe. Our strategy to generate this data was to vary the input parameters (primary emissions of different aerosol types, and primary emissions of gas phase species, which served as precursors for secondary aerosol, as well as meteorological parameters; 41 parameters in total), as listed in Table 1 . To sample this parameter space efficiently, we employed a Latin Hypercube sampling approach to assemble input parameter combinations for 1800 different scenarios for the training dataset and 120 scenarios as the testing dataset, similar to the procedure used in Hughes et al. [20]. All scenarios were run with 10000 computational particles. They started at 6:00 a.m. local time and used a simulation time of $24 \mathrm{~h}$, saving the hourly output.

We obtained the daily near-surface temperature from the CESM2 $\left(0.9^{\circ}\right.$ by $1.25^{\circ}$ resolution $)$ fully-coupled historical simulations [31]. For each latitude and day of year (DOY) over the years from 1970 to 2014, we retrieved the maximum and minimum temperatures. For a given pair of latitude and DOY in PartMC-MOSAIC, the temperature was then sampled between the maximum and minimum temperatures at the nearest latitude in CESM2 with the same DOY. Gas 
Table 1: List of input parameters and their sampling ranges to construct the training and testing scenarios. The variables $D_{\mathrm{g}}, \sigma_{\mathrm{g}}, E_{\mathrm{a}}$ refer to geometric mean diameter, geometric standard deviation, and number emission flux, respectively.

\begin{tabular}{|c|c|}
\hline Parameters & Range \\
\hline Environmental Variable & \\
\hline Relative humidity $(\mathrm{RH})$ & {$[0.1,1)$ or $[0.4,1)$} \\
\hline Latitude & $\left(70^{\circ} \mathrm{S}, 70^{\circ} \mathrm{N}\right)$ or $\left(90^{\circ} \mathrm{S}, 90^{\circ} \mathrm{N}\right)$ \\
\hline Day of Year & {$[1,365]$} \\
\hline Temperature & based on latitude and day of year \\
\hline \multicolumn{2}{|l|}{ Gas Phase Emissions Scaling Factor } \\
\hline \multicolumn{2}{|l|}{$\mathrm{SO}_{2}, \mathrm{NO}_{2}, \mathrm{NO}, \mathrm{NH}_{3}, \mathrm{CO}, \mathrm{CH}_{3} \mathrm{OH}$} \\
\hline \multicolumn{2}{|l|}{ ALD2 (Acetaldehyde), ANOL (Ethanol), } \\
\hline \multicolumn{2}{|l|}{ AONE (Acetone), DMS (Dimethyl sulfide), } \\
\hline \multicolumn{2}{|c|}{ ETH (Ethene), HCHO (Formaldehyde), $\quad[0,200 \%]$} \\
\hline \multicolumn{2}{|l|}{ ISOP (Isoprene), OLEI (Internal olefin carbons), } \\
\hline \multicolumn{2}{|l|}{ OLET (Terminal olefin carbons), } \\
\hline \multicolumn{2}{|l|}{ PAR (Paraffin carbon), TOL (Toluene), XYL (Xylene) } \\
\hline \multicolumn{2}{|l|}{ Carbonaceous Aerosol Emissions (one mode) } \\
\hline$D_{\mathrm{g}}$ & {$[25 \mathrm{~nm}, 250 \mathrm{~nm}]$} \\
\hline & {$[1.4,2.5]$} \\
\hline $\mathrm{BC} / \mathrm{OC}$ mass ratio & {$[0,100 \%]$} \\
\hline$E_{\mathrm{a}}$ & {$\left[0,1.6 \times 10^{7} \mathrm{~m}^{-2} \mathrm{~s}^{-1}\right]$} \\
\hline \multicolumn{2}{|l|}{ Sea Salt Emissions (two modes) } \\
\hline$D_{\mathrm{g}, 1}$ & {$[180 \mathrm{~nm}, 720 \mathrm{~nm}]$} \\
\hline$\sigma_{\mathrm{g}, 1}$ & {$[1.4,2.5]$} \\
\hline$E_{\mathrm{a}, 1}$ & {$\left[0,1.69 \times 10^{5} \mathrm{~m}^{-2} \mathrm{~s}^{-1}\right]$} \\
\hline$D_{\mathrm{g}, 2}$ & {$[1 \mu \mathrm{m}, 6 \mu \mathrm{m}]$} \\
\hline$\sigma_{\mathrm{g}, 2}^{\circ}$ & {$[1.4,2.5]$} \\
\hline$E_{\mathrm{a}, 2}$ & {$\left[0,2380 \mathrm{~m}^{-2} \mathrm{~s}^{-1}\right]$} \\
\hline OC fraction & {$[0,20 \%]$} \\
\hline \multicolumn{2}{|l|}{ Dust Emissions (two modes) } \\
\hline$D_{\mathrm{g}, 1}$ & {$[80 \mathrm{~nm}, 320 \mathrm{~nm}]$} \\
\hline$\sigma_{\mathrm{g}, 1}$ & {$[1.4,2.5]$} \\
\hline$E_{\mathrm{a}, 1}$ & {$\left[0,5.86 \times 10^{5} \mathrm{~m}^{-2} \mathrm{~s}^{-1}\right]$} \\
\hline$D_{\mathrm{g}, 2}$ & {$[1 \mu \mathrm{m}, 6 \mu \mathrm{m}]$} \\
\hline$\sigma_{\mathrm{g}, 2}{ }_{2}$ & {$[1.4,2.5]$} \\
\hline$E_{\mathrm{a}, 2}$ & {$\left[0,2380 \mathrm{~m}^{-2} \mathrm{~s}^{-1}\right]$} \\
\hline \multicolumn{2}{|l|}{ Restart Timestamp } \\
\hline Timestamp & {$[0,25$ hours $]$} \\
\hline
\end{tabular}

initial conditions and emission rates were based on Riemer et al. [24]. We sampled the gas phase emissions using a scaling factor (0\%-200\%) for the gas phase species listed in Table 1 . To create aerosol initial conditions with realistic mixing states we adopted the following approach: We performed a first set of runs, starting with the aerosol initial concentrations set to zero for all the simulations (the "initial runs"). We then repeated the same set of runs, but replaced the aerosol initial condition with a randomly sampled population from the initial runs (the "restart runs"). For the training and testing datasets, we only used the results from the restart runs. The size distribution parameters for the aerosol emissions were prescribed as log-normal, with geometric mean diameter $\left(D_{\mathrm{g}}\right)$ and geometric standard deviation $\left(\sigma_{\mathrm{g}}\right)$ depending on the particle type.

Among the 1800 scenarios, two-thirds contained sea salt emissions. We uniformly sampled the relative humidity for these scenarios from a range of $40 \%$ to $100 \%$, and latitude from a range of $90^{\circ} \mathrm{S}$ to $90^{\circ} \mathrm{N}$. The latitude governs the solar zenith angle and the length of the day, which are important for the photochemical production of secondary aerosol. We included initial concentration [32], and emissions [33] of the biogenic trace gas dimethylsulfide (DMS) for the scenarios with sea salt emission, as it is a precursor of sulfate aerosol in marine environments [34]. For the scenarios without sea salt emissions, we uniformly sampled the relative humidity from $10 \%$ to $100 \%$, and latitude from $70^{\circ} \mathrm{S}$ to $70^{\circ} \mathrm{N}$. Similarly, two-thirds of all scenarios contained dust emissions. Hence we have in total four types of scenarios with a frequency ratio of occurrence of $4: 2: 2: 1$. Four-ninths of the scenarios have both sea salt and dust emissions, and one-ninth of the scenarios have neither sea salt nor dust emissions. 


\section{Aerosol mixing state indices definition}

The mixing state index $\chi[16]$ quantifies where an aerosol population lies on the continuum of external to internal mixing, that is, how "spread out" the chemical species are over an aerosol population, see Figure 2 for an illustration. We will focus here on the aerosol mixing state of sub-micron particles $\left(\mathrm{PM}_{1.0}\right)$ due to their impact on light scattering and absorption [35], and contribution to CCN formation [36, 37, 38].

The mixing state index $\chi$ is given by the affine ratio of the average particle species diversity $\left(D_{\alpha}\right)$ and bulk population species diversity $\left(D_{\gamma}\right)$ as

$$
\chi=\frac{D_{\alpha}-1}{D_{\gamma}-1} .
$$

The diversities $D_{\alpha}$ and $D_{\gamma}$ are calculated as follows. First, the per-particle mixing entropies $H_{i}$ are determined for each particle using the per-particle species mass fractions:

$$
H_{i}=\sum_{a=1}^{A}-p_{i}^{a} \ln p_{i}^{a} .
$$

Here, $A$ is the number of distinct aerosol species and $p_{i}^{a}$ is the mass fraction of species $a$ in particle $i$. These values are then averaged (mass-weighted) over the entire population to find the average particle entropy, $H_{\alpha}$, and the average particle species diversity, $D_{\alpha}$, by

$$
\begin{aligned}
H_{\alpha} & =\sum_{i=1}^{N_{\mathrm{p}}} p_{i} H_{i}, \\
D_{\alpha} & =e^{H_{\alpha}},
\end{aligned}
$$

where $N_{\mathrm{p}}$ is the total number of particles in the population, and $p_{i}$ is the mass fraction of particle $i$ in the population. Finally, the bulk entropy, $H_{\gamma}$, and bulk diversity, $D_{\gamma}$, is calculated as:

$$
\begin{aligned}
& H_{\gamma}=\sum_{a=1}^{A}-p^{a} \ln p^{a}, \\
& D_{\gamma}=e^{H_{\gamma}} .
\end{aligned}
$$

Importantly, the definition of the "species" to calculate $D_{\alpha}$ and $D_{\gamma}$ depends on the application or may be dictated by the instrumentation used to estimate per-particle mass fractions. For example, in some previous studies, elemental species (e.g., N, O, C) have been used [3, 39, 17], while others used molecular species (e.g., $\mathrm{SO}_{4}, \mathrm{NH}_{4}, \mathrm{NO}_{3}$ ) [4, 5, 7]. Yet other studies employed surrogate species where several species with similar properties were grouped together, such as hygroscopic/non-hygroscopic species [19, 20], or volatile/non-volatile species [40]. The choice of which species to group as one surrogate species is then motivated by the science question under investigation.

Here we compare and contrast the aerosol mixing state indices defined in three different ways, namely based on model chemical species abundance $\left(\chi_{\mathrm{a}}\right)$, based on the mixing of optically absorbing and non-absorbing species $\left(\chi_{\mathrm{o}}\right)$, and based on the mixing of hygroscopic and non-hygroscopic species $\left(\chi_{\mathrm{h}}\right)$. Table 2 shows the specific definitions of these aerosol mixing state indices. The index $\chi_{\mathrm{a}}$ was defined based on all six model aerosol species. For $\chi_{\mathrm{o}}$, we considered two surrogate species, black carbon (absorbing) and all other aerosol species grouped together (assumed to be non-absorbing). Thus, a lower value in $\chi_{\mathrm{o}}$ refers to the case where the absorbing species black carbon and the sum of all other (non-absorbing) species are more externally mixed. Similarly, $\chi_{\mathrm{h}}$ was also calculated from two surrogate species. We combined black carbon, dust, and primary organic matter as one surrogate species, given their comparatively low hygroscopicities, and $\mathrm{NaCl}, \mathrm{SOA}$, and sulfate as the other surrogate species. Here a lower value in $\chi_{\mathrm{h}}$ represents the case where hygroscopic and non-hygroscopic species tend to be present in separate particles.

Figure 2 illustrates the concept of different aerosol mixing state indices corresponding to a particle population which consists of six particles and six chemical species that are present in equal amounts in the bulk. Moving from left to right, the bulk composition for each population remains the same, but the population becomes more internally mixed. That is, the particles become more similar to each other. This is reflected in an increasing mixing state index, and this applies to all three mixing state indices individually. Another lesson is that the mixing state index depends on how we define the surrogate species. In our example, the population with a mixing state index of $\chi_{\mathrm{a}}=20 \%$ has $\chi_{\mathrm{o}}=63 \%$ and $\chi_{\mathrm{h}}=67 \%$. For this example, the population is quite externally mixed with respect to all chemical model species, but appears more internally mixed with respect to hygroscopicity or optical properties. A consequence of the definition of the surrogate species as supersets of the chemical model species is that, for the extreme cases of $\chi_{\mathrm{a}}=100 \%$ and 
Table 2: Aerosol mixing state indices definition. Six aerosol species (see Table 3) are used in calculating the aerosol mixing state indices based on different definitions. We calculate $\chi_{\mathrm{a}}$ based on all six aerosol model species. The mixing state indices $\chi_{\mathrm{o}}$ and $\chi_{\mathrm{h}}$ are based on two surrogate species.

\begin{tabular}{ll}
\hline Aerosol Mixing State Index (abbr) & Grouped Species \\
\hline abundance $\left(\chi_{\mathrm{a}}\right)$ & $(\mathrm{bc}),(\mathrm{dst}),(\mathrm{ncl}),(\mathrm{pom}),(\mathrm{soa}),(\mathrm{so} 4)$ \\
optical property $\left(\chi_{\mathrm{o}}\right)$ & $(\mathrm{bc}),(\mathrm{dst}, \mathrm{ncl}, \mathrm{pom}, \mathrm{soa}, \mathrm{so})$ \\
hygroscopicity $\left(\chi_{\mathrm{h}}\right)$ & $(\mathrm{bc}, \mathrm{dst}, \mathrm{pom}),(\mathrm{ncl}, \mathrm{soa}, \mathrm{so} 4)$ \\
\hline
\end{tabular}

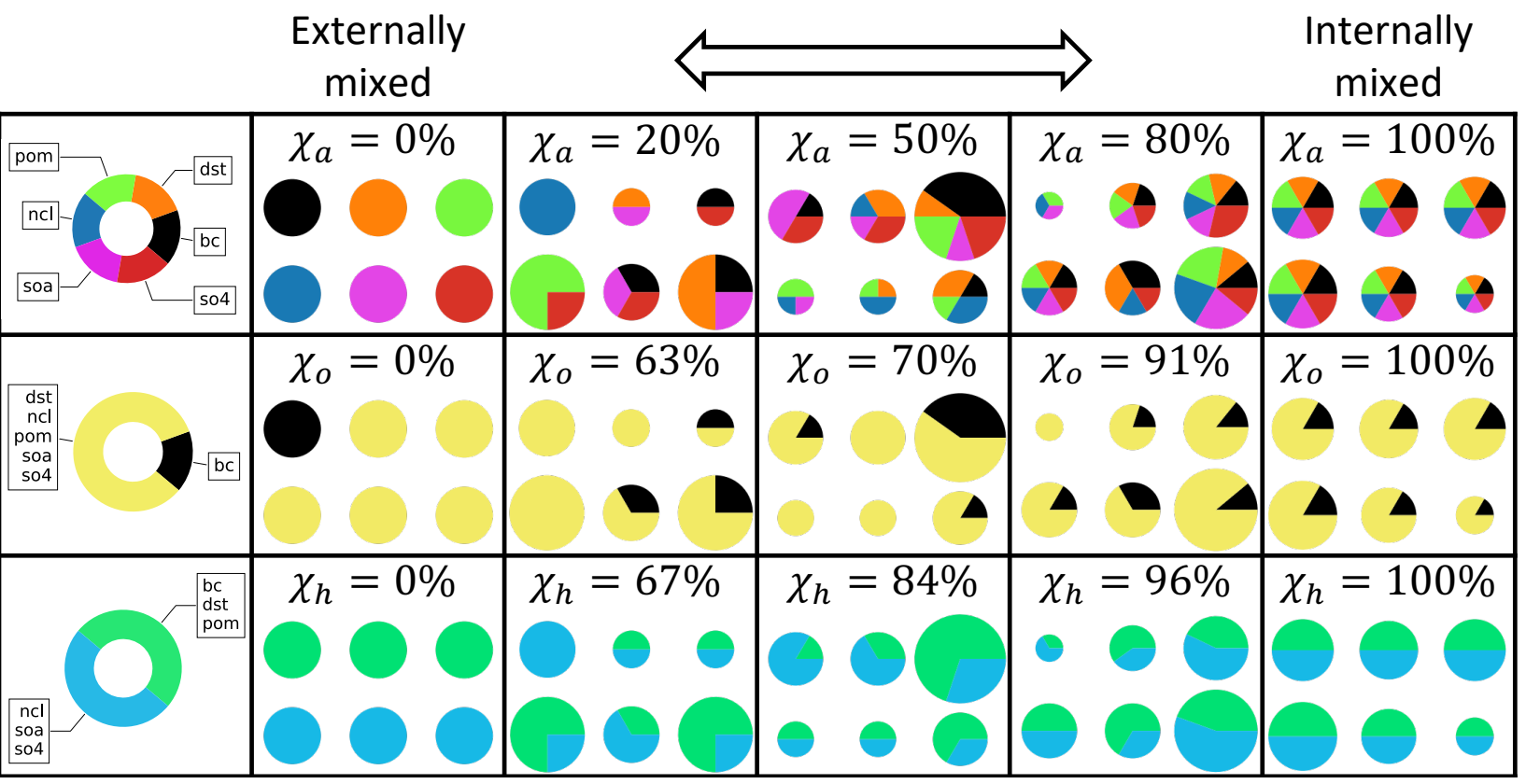

Figure 2: The concept of aerosol mixing state indices $\chi_{\mathrm{a}}, \chi_{\mathrm{o}}$, and $\chi_{\mathrm{h}}$ for a population consisting of six chemical species, where the bulk mass fractions of species are the same for all six species

$\chi_{\mathrm{a}}=0 \%, \chi_{\mathrm{o}}$ and $\chi_{\mathrm{h}}$ are also $100 \%$ or $0 \%$, respectively. The reverse, however, is not true. That is, $\chi_{\mathrm{o}}=100 \%$ does not imply $\chi_{\mathrm{a}}=100 \%$. In general, the exact mapping between $\chi_{\mathrm{a}}, \chi_{\mathrm{h}}$ and $\chi_{\mathrm{o}}$ is not straightforward and depends on the relative abundance of the different (surrogate) species.

\section{PartMC-MOSAIC emulator development and application}

\subsection{Feature definitions}

The features for the emulator were selected according to the following two criteria. First, the features should be available within both the PartMC-MOSAIC and CESM simulations, so that we have consistent features for training, validation, and application processes. Second, the features should be physically or chemically related to the aerosol properties. A subset of the aerosol and gas phase species and environmental variables were selected as features in this study (Table 3 ). The specific aerosol species were defined by the modal aerosol module (MAM4 [41, 23]) and PartMC-MOSAIC.

\subsection{Emulator development}

We used eXtreme Gradient Boosting (XGBoost [42]) as the machine learning algorithm for our emulator development. Built upon the Gradient Boosting [43] framework, XGBoost is highly efficient, flexible, and portable. It can not only handle complex nonlinear interactions and collinearity among predictors, but also provides a parallel implementation that solves data science problems (particularly with structured data) efficiently. It has been successfully used in various fields such as physics [44], medical research [45], and ornithology [46]. Here, we developed three emulators, corresponding to the three aerosol mixing state indices outlined in Section 3. 
Table 3: Feature (variable) definitions in CESM and PartMC-MOSAIC. Type: A (aerosol), G (gas), E (environmental).

\begin{tabular}{|c|c|c|c|c|}
\hline Feature Name & CESM & PartMC & Type & Unit \\
\hline black carbon & $\begin{array}{l}\text { (bc_a1_SRF, } \\
\text { bc_a4_SRF) }\end{array}$ & $\mathrm{BC}$ & A & $\mathrm{kg} / \mathrm{kg}$ \\
\hline mineral dust & $\begin{array}{l}\text { (dst_a1_SRF, } \\
\text { dst_a2_SRF) }\end{array}$ & OIN & $\mathrm{A}$ & $\mathrm{kg} / \mathrm{kg}$ \\
\hline sea salt & $\begin{array}{l}\text { (ncl_a1_SRF, } \\
\text { ncl_a2_SRF) }\end{array}$ & $(\mathrm{Na}, \mathrm{Cl})$ & A & $\mathrm{kg} / \mathrm{kg}$ \\
\hline primary organic matter & $\begin{array}{l}\text { (pom_a1_SRF, } \\
\text { pom_a4_SRF) }\end{array}$ & $\mathrm{OC}$ & A & $\mathrm{kg} / \mathrm{kg}$ \\
\hline secondary organic aerosol & $\begin{array}{l}\text { (soa_a1_SRF, } \\
\text { soa_a2_SRF) }\end{array}$ & $\begin{array}{l}\text { (ARO1, ARO2, } \\
\text { ALK1, OLE1, } \\
\text { API1, API2, } \\
\text { LIM1, LIM2) }\end{array}$ & $\mathrm{A}$ & $\mathrm{kg} / \mathrm{kg}$ \\
\hline sulfate & $\begin{array}{l}\text { (so4_a1_SRF, } \\
\text { so4_a2_SRF) }\end{array}$ & $\mathrm{SO} 4$ & $\mathrm{~A}$ & $\mathrm{~kg} / \mathrm{kg}$ \\
\hline dimethyl sulfide & DMS & DMS & G & $\mathrm{mol} / \mathrm{mol}$ \\
\hline hydrogen peroxide & $\mathrm{H} 2 \mathrm{O} 2$ & $\mathrm{H} 2 \mathrm{O} 2$ & G & $\mathrm{mol} / \mathrm{mol}$ \\
\hline sulfuric acid & $\mathrm{H} 2 \mathrm{SO} 4$ & $\mathrm{H} 2 \mathrm{SO} 4$ & G & $\mathrm{mol} / \mathrm{mol}$ \\
\hline ozone & $\mathrm{O} 3$ & $\mathrm{O} 3$ & G & $\mathrm{mol} / \mathrm{mol}$ \\
\hline semi-volatile organic gas & SOAG & $\begin{array}{l}\text { (ARO1, ARO2, } \\
\text { ALK1, OLE1, } \\
\text { API1, API2, } \\
\text { LIM1, LIM2) }\end{array}$ & G & $\mathrm{mol} / \mathrm{mol}$ \\
\hline sulfur dioxide & $\mathrm{SO} 2$ & $\mathrm{SO} 2$ & G & $\mathrm{mol} / \mathrm{mol}$ \\
\hline air temperature & $\mathrm{T}$ & temperature & $\mathrm{E}$ & \\
\hline relative humidity & RELHUM & relative_humidity & E & \\
\hline solar zenith angle & SZA & solar_zenith_angle & $\mathrm{E}$ & radian \\
\hline
\end{tabular}
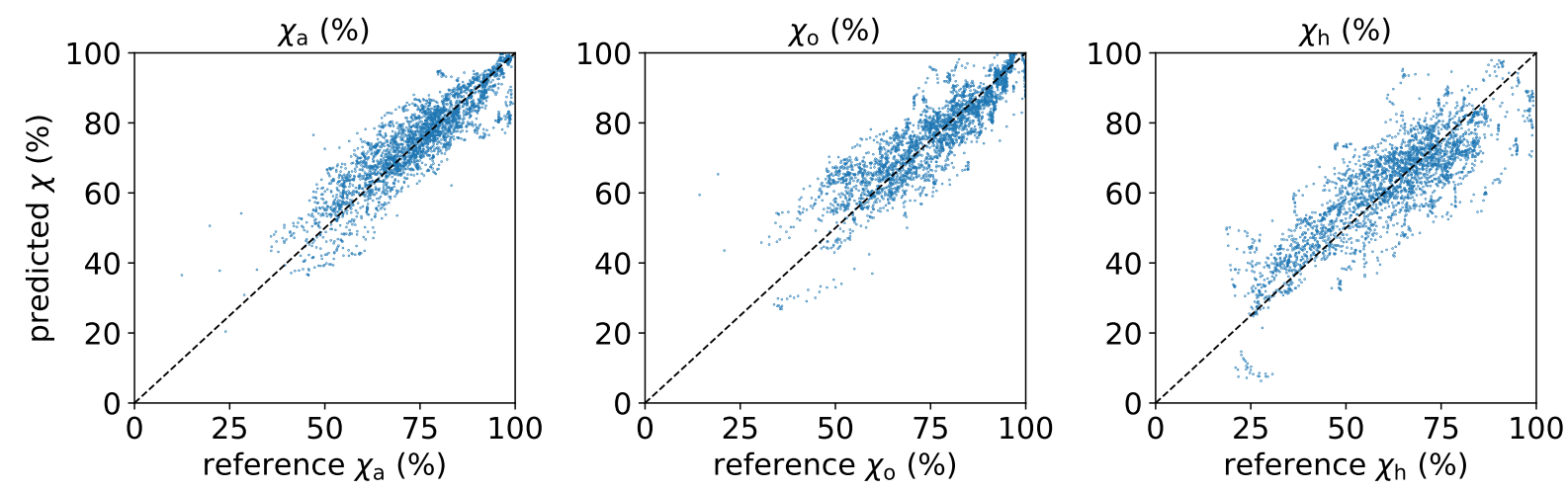

Figure 3: Emulator performance comparing the predicted mixing state indices with the reference indices, as measured on the testing data set.

For each aerosol mixing state index, the emulator was trained from the entire 1800 training scenarios with hyperparameters (number of gradient boosted trees, maximum tree depth for base learners, and boosting learning rate) previously determined by using grid search with 10 -fold cross-validation. Figure 3 shows the performance of emulators using the testing scenarios, which have never been seen by the training process. Table 4 shows the predictive accuracy of the XGBoost-based emulators compared to the benchmark using ordinary least squares. These metrics are important to keep in mind when interpreting the results in Section 5 The error for any predicted mixing state index can be roughly thought of as $\pm 10 \%$, and somewhat higher for $\chi_{\mathrm{h}}$. 
Table 4: Evaluation of mixing state emulators using the testing data set. The metrics are root-mean-square error (RMSE), mean absolute error (MAE), median absolute deviation (MAD), index of agreement ( $d$ [47]), Pearson correlation coefficient (PCC), and coefficient of determination $\left(r^{2}\right)$. The emulators from linear regression with ordinary least squares (OLS) are examined as a benchmark. The p-value $(<0.001)$ applies for both methods using the F-test.

\begin{tabular}{ccccccc}
\hline$\chi$ & RMSE & MAE & MAD & $d$ & PCC & $r^{2}$ \\
\hline \multicolumn{7}{c}{ XGBoost Emulators } \\
\hline$\chi_{\mathrm{a}}$ & 0.062 & 0.047 & 0.036 & 0.943 & 0.894 & 0.796 \\
$\chi_{\mathrm{o}}$ & 0.069 & 0.053 & 0.041 & 0.935 & 0.884 & 0.778 \\
$\chi_{\mathrm{h}}$ & 0.094 & 0.074 & 0.061 & 0.907 & 0.836 & 0.696 \\
\hline \multicolumn{6}{c}{ Linear Regression with Ordinary Least } & Squares (OLS) \\
\hline$\chi_{\mathrm{a}}$ & 0.107 & 0.084 & 0.067 & 0.767 & 0.642 & 0.395 \\
$\chi_{\mathrm{o}}$ & 0.109 & 0.085 & 0.073 & 0.779 & 0.673 & 0.452 \\
$\chi_{\mathrm{h}}$ & 0.134 & 0.107 & 0.088 & 0.731 & 0.618 & 0.382 \\
\hline
\end{tabular}

\subsection{Emulator application}

Applying the emulator is fast, compared to embedding PartMC-MOSAIC into regional models or ESMs for each grid cell. Here we used CESM (version 2.1.0 [48]) component set, FHIST (Community Atmospheric Model standalone runs), as a testbed for our emulator application. This component set represents a typical historical simulation in the Community Atmospheric Model (CAM6), which uses an active Atmosphere and Land with prescribed Sea-Surface Temperatures (SSTs) and sea-ice extent, and a 1 degree finite volume dycore with the forcing data available from 1979 to 2015. MAM4 is the default aerosol module of this component set, which predicts the aerosol size distribution with four lognormal modes (Aitken, accumulation, coarse, and primary carbon modes). The model treats the microphysical aging of the primary carbonaceous aerosols in the atmosphere [23]. It contains six aerosol species, namely black carbon, dust, sea salt, primary organic matter, secondary organic aerosol, and sulfate across four modes. We ran the model for the year 2011 with 6 years $(2005-2010)$ spinup [49, 50]. The simulation was conducted at a resolution of $0.9^{\circ}$ latitude $\times 1.25^{\circ}$ longitude along with prescribed land, sea-ice, and ocean. We stored the instantaneous outputs every three hours in the simulation, which yielded 2920 timestamps for each surface-layer grid cell for the entire year of simulation time.

For reference, Figures S1 and S2 illustrate the seasonal variation and spatial distribution of the sub-micron aerosol species at the global scale. As we discussed in Text S1, the distributions were in line with previous studies [51, 52, 53, 54, 55, 56, 57, 58]. It is worth mentioning that our simulation does not focus on optimizing the parameterizations of CESM. We used the default setting to conduct the simulations as a basis for estimating the different mixing state indices with the corresponding emulator in each grid cell.

\section{Global aerosol mixing state indices}

In this section, we will first present the seasonal variation and spatial distribution of the three aerosol mixing state indices as obtained from applying the emulators. We will then put these findings in context with available observations, and finish this section with quantifying the relationship between the three indices as they were predicted for the entire model domain.

\subsection{Seasonal variation and spatial distribution of aerosol mixing state indices}

We averaged the $3 \mathrm{~h}$ instantaneous values of aerosol mixing state index for the two seasons (December-January-February, DJF, and June-July-August, JJA) to determine their seasonal variations and spatial distributions. We masked the areas where the mass fraction of any one species is higher than $99 \%$ (for $\chi_{\mathrm{o}}$ ) or $97.5 \%$ (for $\chi_{\mathrm{a}}$ and $\chi_{\mathrm{h}}$ ). The rationale for applying these masks is that only when at least two species are present in a given location does it make sense to quantify mixing state.

Figure 4 shows the global maps of the aerosol mixing state index $\chi_{\mathrm{a}}$ based on chemical species abundance. In DJF, $\chi_{\text {a }}$ ranged from $27 \%$ to $96 \%$ over the globe, with a mean of $75 \%$. Of note is the region across the Atlantic from West and Central Africa to the northeast coast of South America, where $\chi_{\mathrm{a}}$ was smaller than 40\%. In this region, dust and primary organic matter were prevalent, with contributions of sea salt (Figure S2), and so this result can be interpreted to mean that these species are comparatively, although not completely, externally mixed.

In contrast, aerosol species were rather internally mixed $\left(\chi_{\mathrm{a}}>80 \%\right)$ over North America, the North Atlantic Ocean, the Arctic Ocean, East Asia, and the North Pacific Ocean. The aerosol composition varied from region to region. Briefly, 
(a) DJF

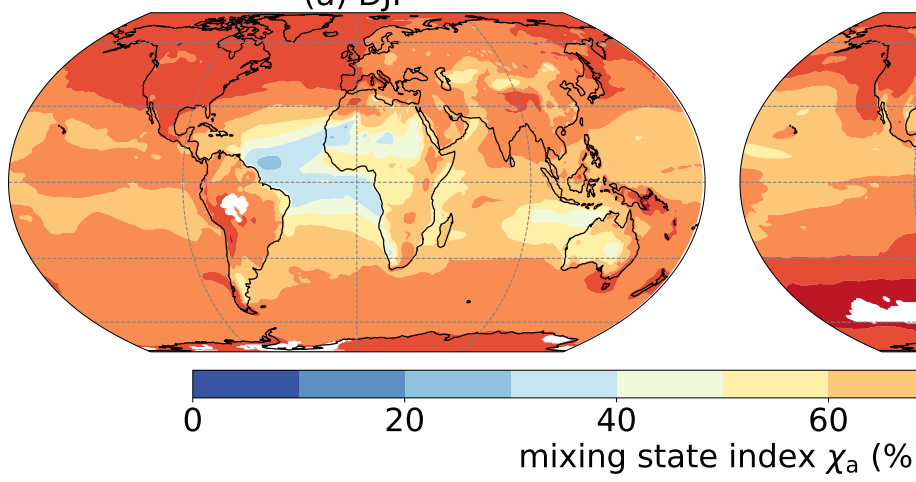

(b) JJA

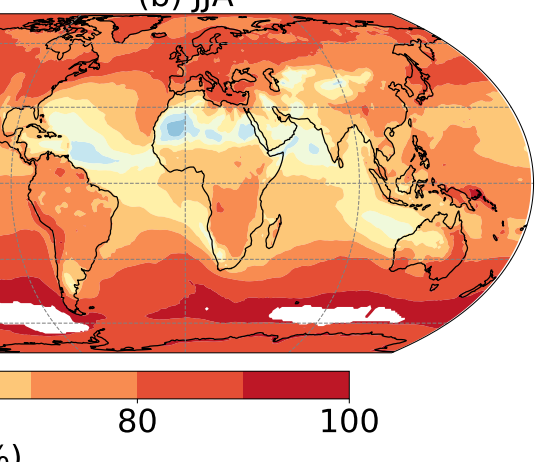

Figure 4: Average mixing state index $\chi_{a}$ based on chemical abundance in seasons (a) DJF and (b) JJA. The areas with the mass fraction of any one species higher than $97.5 \%$ are masked.

in DJF, aerosols over the continents of those regions were dominated by primary organic matter, secondary organic aerosol, and sulfate, while sea salt and sulfate governed the aerosol composition over the oceans. The high values of $\chi_{\mathrm{a}}$ suggest that the species in these locations are rather internally mixed.

In JJA, $\chi_{\mathrm{a}}$ varied within a range of $23 \%-96 \%$ and a mean of $77 \%$, which is similar to DJF, but exhibited a different spatial pattern compared to DJF. The extent of regions with predominantly externally mixed aerosols $\left(\chi_{\mathrm{a}}<40 \%\right)$ decreased, while those with internally mixed aerosols $\left(\chi_{\mathrm{a}}>80 \%\right)$ increased. The lowest values of $\chi_{\mathrm{a}}$ shifted from the North Atlantic Ocean to Western and Northern Africa. Significant differences between seasons existed in the Gulf of Guinea and the Arabian Sea. Compared to DJF, the mixing state index increased greatly over the Gulf of Guinea $\left(12^{\circ} \mathrm{S}-12^{\circ} \mathrm{N}, 12^{\circ} \mathrm{W}-12^{\circ} \mathrm{E}\right)$ for JJA, from $\chi_{\mathrm{a}}=45 \%$ to $\chi_{\mathrm{a}}=62 \%$. The bulk composition of the aerosol also changed in this region between seasons. Combining this information, in DJF the submicron aerosol was mainly primary organic matter and dust, and it was comparatively externally mixed, while in JJA it was mainly primary organic matter, secondary organic matter, and sulfate comparatively, and was internally mixed. In contrast, $\chi_{\mathrm{a}}$ over the Arabian Sea $\left(0-25^{\circ} \mathrm{N}, 50-75^{\circ} \mathrm{E}\right)$ experienced a drastic decrease from DJF to JJA, where a more internal mixture of sulfate and primary organic matter was replaced by a more external mixture dominated by sea salt, sulfate, and dust. Over the Southern ocean $\left(30-60^{\circ} S\right)$, $\chi_{\mathrm{a}}$ values increased during JJA to values of nearly $90 \%$. The bulk composition of the aerosol, however, was mainly sea salt (over $80 \%$ mass fraction), with only small contributions of the other aerosol species.

Figures $5 \mathrm{a}$ and $\mathrm{b}$ show the global distribution of the aerosol mixing state index $\chi_{\mathrm{o}}$ (based on the mixing of optically absorbing and non-absorbing species) for DJF and JJA, and, for reference, Figures $5 \mathrm{k}$ and d depict the corresponding bulk mass fractions of black carbon. We masked out the areas where the bulk mass fraction of black carbon is lower than $1 \%$ to only evaluate $\chi_{\mathrm{o}}$ where black carbon is present in non-negligible amounts.

In DJF, $\chi_{\mathrm{o}}$ ranged from $49 \%$ to $94 \%$. This range is smaller than the range for $\chi_{\mathrm{a}}$ although the global mean (75\%) was close to that of $\chi_{\mathrm{a}}$. The high values of $\chi_{\mathrm{o}}$ suggest that in most of the regions around the globe, black carbon was at least $49 \%$ internally mixed, and even more so in the continental regions, although a complete internal mixture was not reached anywhere. This means that $\mathrm{BC}$ is not evenly distributed over all particles, but it is also not exclusively confined to some particles. We can refer to the middle row in Fig. 2 for an illustration of what the particle population might look like going from $\chi_{\mathrm{o}}=63 \%$ to $91 \%$. Note that BC-free particles may co-exist with BC-containing particles under these conditions.

A high degree of internal mixture ( $\chi_{\mathrm{o}}$ larger than $80 \%$, meaning BC is rather spread out over the aerosol population) was predicted over the Arabian Sea, Bay of Bengal, India, and south-west of China. These are areas where the mass mixing ratios of black carbon were relatively high, and $\chi_{\mathrm{a}}$ was also relatively high. It suggests that black carbon was internally mixed with other species, with the most abundant species being primary organic matter and sulfate. However, high values of $\chi_{\mathrm{o}}$ coincide with low values of $\chi_{\mathrm{a}}$ over the Gulf of Guinea. This can be attributed to the external mixture of the non-black-carbon species (dust and secondary organic aerosol) at this location.

In JJA, $\chi_{\mathrm{o}}$ had a range of $49 \%$ to $95 \%$ and a global mean of $76 \%$, overall similar to the DJF season. Black carbon was more internally mixed in Southern Africa in JJA. In this area, it was mainly primary organic matter that formed an internal mixture with black carbon. Another pronounced change compared to DJF occurred in Eastern China, where the 
(a) DJF
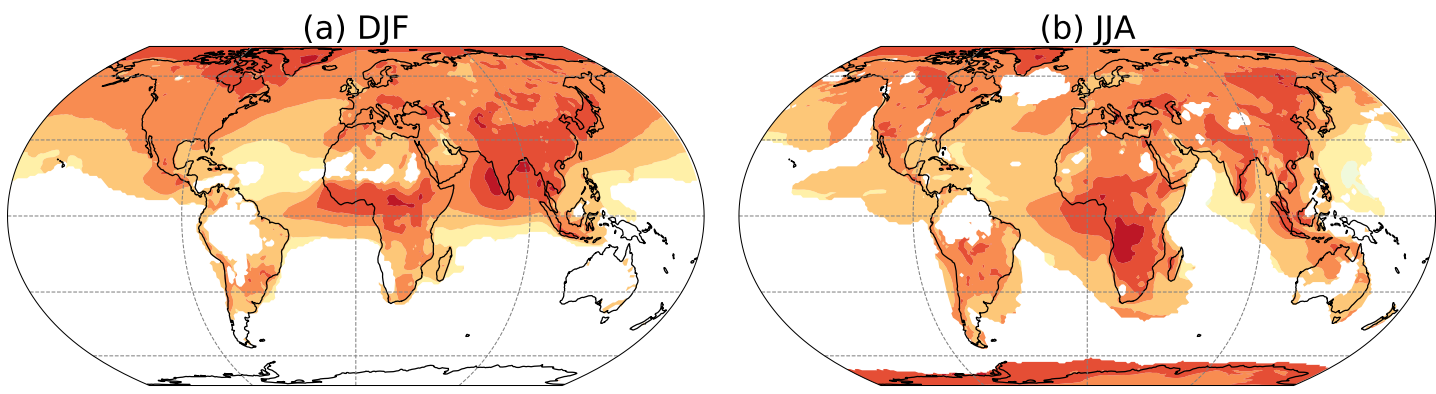

020

40

mixing state index $\chi_{0}$

60

(\%)

(c) DJF
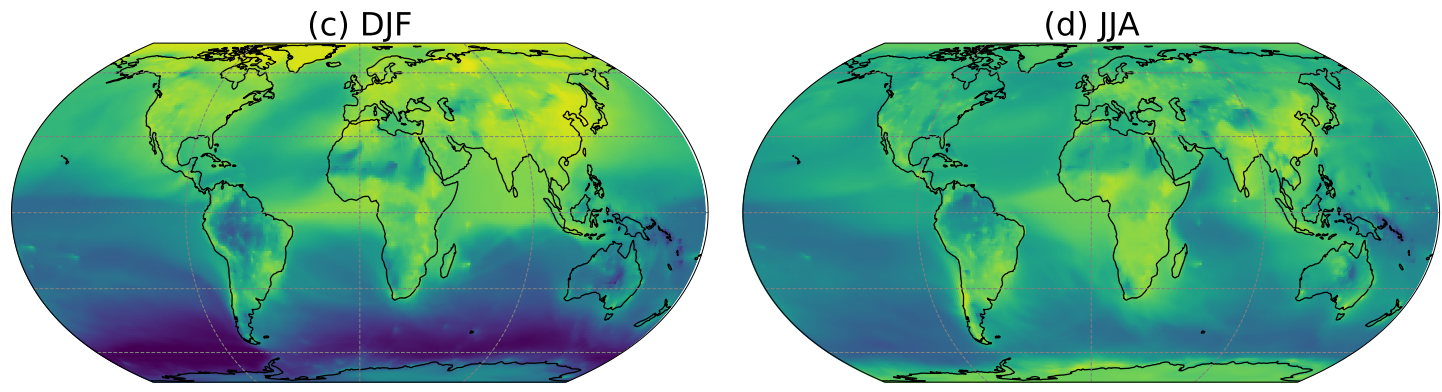

$10^{0}$

$10^{-2}$

$10^{-1}$

mass fraction of bc (\%)

Figure 5: Average mixing state index $\chi_{\mathrm{o}}$ (based on the mixing of optically absorbing and non-absorbing species) and the mass fraction of black carbon in submicron aerosol. Mixing state index $\chi_{\mathrm{o}}$ in seasons (a) DJF and (b) JJA. Mass fraction of black carbon in seasons (c) DJF and (d) JJA. The mask in (a) and (b) is based on the mass fraction in (c) and (d), respectively, where the areas with mass fraction of black carbon lower than $1 \%$ or higher than $99 \%$ are masked.

black carbon was internally mixed with an elevated level of primary organic matter, sulfate, and secondary organic aerosol. In general, areas with high mass fractions of black carbon were associated with higher values of $\chi_{\mathrm{o}}$, meaning that in polluted urban regions, black carbon existed in an internal mixture with other aerosol species. In contrast, areas with low black carbon mass fractions, for example over the oceans, were associated with lower values of $\chi_{\mathrm{o}}$ (between an internal and external mixture). Slightly decreased values of $\chi_{\mathrm{o}}$ (10 percentage points) were predicted over the Arctic $\left(66.5-90^{\circ} \mathrm{N}\right)$, where the submicron aerosol was dominated by increased primary organic carbon and decreased black carbon and sulfate.

Figure 6 shows the distributions of the aerosol mixing state index $\chi_{\mathrm{h}}$ (based on the mixing of hygroscopic and nonhygroscopic species), and the corresponding mass fraction of non-hygroscopic species (black carbon, dust, and primary organic matter). Similar to Figure 4 we focus on areas where both surrogate species are present with a mass fraction threshold of $2.5 \%$. The mixing state index $\chi_{\mathrm{h}}$ in DJF ranged from $24 \%$ to $90 \%$, with a global mean of $63 \%$. The Arabian Sea, Bay of Bengal, south-west of China, and Mongolia were areas where hygroscopic and non-hygroscopic species existed in a more internal mixture $\left(\chi_{\mathrm{h}}\right.$ larger than $\left.70 \%\right)$. Sulfate and primary organic matter were the most abundant species over these regions (Figure S2). In contrast, hygroscopic and non-hygroscopic species were more externally mixed over the North Atlantic Ocean (near the equator), Southern Africa, and Australia. Here the dominant aerosol species were mineral dust and sea salt. In JJA, $\chi_{\mathrm{h}}$ varied between $19 \%$ and $89 \%$, with a mean of $63 \%$. Over Central Africa and Southern Africa, $\chi_{\mathrm{h}}$ increased to higher values (greater than $60 \%$ ) than the DJF season. Here, primary organic carbon was the dominant non-hygroscopic species, while secondary organic aerosol and sulfate were both present as hygroscopic species. In contrast, $\chi_{\mathrm{h}}$ over the Arabian Sea decreased from DJF to JJA, similar to $\chi_{\mathrm{a}}$. In this region, a predominantly sea salt/dust mixture that was more externally mixed replaced the more internally-mixed primary organic carbon/sulfate mixture present in DJF. 
(a) DJF
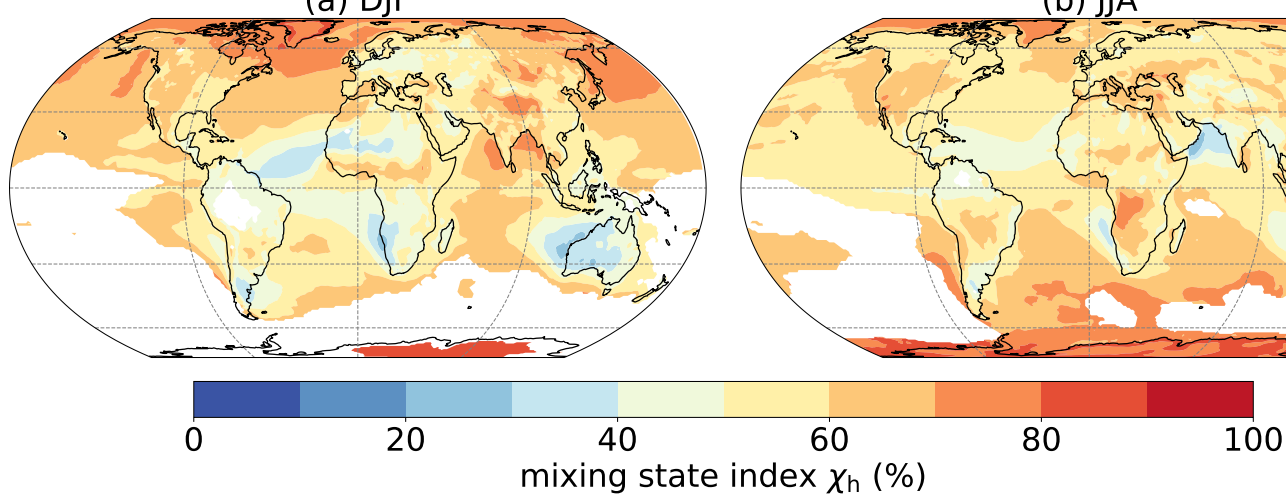

(c) DJF
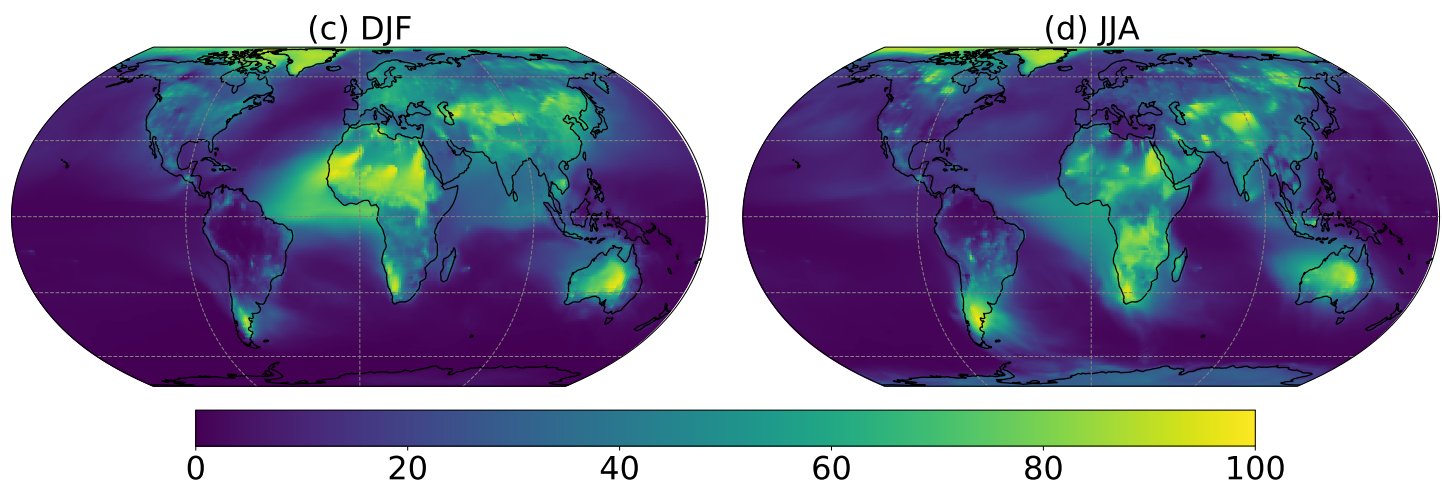

20

40

mass fraction of $(b c+d s t+p o m)(\%)$

Figure 6: Average mixing state index $\chi_{\mathrm{h}}$ (based on the mixing of hygroscopic and non-hygroscopic species) and the mass fraction of non-hygroscopic species (black carbon, dust, and primary organic matter) in submicron aerosol. Mixing state index $\chi_{\mathrm{h}}$ in seasons (a) DJF, and (b) JJA. Mass fraction of non-hygroscopic species in seasons (c) DJF and (d) JJA. The mask in (a) and (b) is based on the mass fraction in (c) and (d), respectively, where the areas with mass fraction of black carbon, dust, and primary organic matter lower than $2.5 \%$ or higher than $97.5 \%$ are masked.

The mixing state indices varied considerably over the oceans. The outflow of biomass burning or dust emission regions in Africa were areas of comparatively external mixtures in terms of species abundance (quantified by $\chi_{\mathrm{a}}$ ), owing to the coexistence of mineral dust or biomass burning aerosol and sea salt aerosol. Judging from the maps for $\chi_{\mathrm{o}}$, plumes of black carbon originating from major biomass burning regions in Africa were initially comparatively internally mixed and then became more externally mixed as the plume was transported over the ocean. This makes sense considering that an increasingly external mixture should form as the carbonaceous plumes mix with sea salt aerosol as they are transported away from the coasts. Another finding is that black carbon is fairly (albeit not completely) internally mixed in highly polluted areas, which is consistent with prior work from modeling [11] and measurements [12]. These studies found that short aging time scales apply to black carbon aerosol in polluted regions. It should be noted that very close to the source an external mixture may apply, but capturing this would require a high spatial resolution down to the kilometer scale.

\subsection{Comparison to observational data}

The comparison to observational data is still challenging at this point, as per-particle mass fractions are needed to determine the mixing state indices and they are difficult to estimate. Here we attempted to compare at least qualitatively to the work by Healy et al. [4] and Ye et al. [5] since they used mixing state indices comparable to our $\chi_{\mathrm{a}}$. For one month during winter 2010, Healy et al. [4] determined a mixing state index for a site in Paris, France, during the MEGAPOLI campaign. Their mixing state index reached values of up to $72 \%$ during periods when the site was dominated by aged pollution from a continental air mass. In contrast, the mixing state index was as low as $37 \%$ when the site was dominated by local pollution. Compared to this, we obtained a value of $\chi_{\mathrm{a}}=79 \%$ for DJF and the grid cell where Paris is located. Ye et al. [5] found a very similar range of mixing state indices (30-70\%) for the Pittsburgh, 
PA, region, with values closer to $70 \%$ outside of the downtown area. They used measurements from July 2016 and January/February 2017 for this analysis. Our values for DJF and JJA for this region are $81 \%$ and $83 \%$, respectively. A direct comparison of our results and observations like these is generally challenging since point measurements in an urban environment are not directly comparable to a global modeling grid cell. However, it is encouraging that our results are relatively close to the observations. Clearly, it would be beneficial to have more observations available for model-observation comparisons, especially from regions that are not dominated by local sources. In addition, difficulties in a comparison may arise when the species list used in the observations is not easily mapped onto model species.

Our $\chi_{\mathrm{o}}$ index can be related to observational studies that use SP2 measurements. Raatikainen et al. [59] conducted measurements in the Finish Arctic during winter 2011-2012 and found that the number fraction of BC-containing particles was on average $24 \%$, and that those BC-containing particles were thickly coated. While this study did not provide quantitative mixing state index calculations, it is an important finding that BC-containing particles (with various amounts of coatings) co-exist with BC-free particles, and our result of $\chi_{\mathrm{o}} \approx 77 \%$ for this area is consistent with this. As we see from Figure 2, a $\chi_{\mathrm{o}}$ value of $77 \%$ could correspond to a population where only some particles contain BC, but where BC-containing particles have a substantial non-BC fraction. Representing this mixing state is a challenge for many aerosol models used on the global scale that assume internal mixtures, but important for estimating aerosol optical properties accurately [60].

\subsection{Relationship amongst the three mixing state indices}

Figure 7 shows the correlation (with p-value $<0.001$ ) among the aerosol mixing state indices $\chi_{\mathrm{a}}, \chi_{\mathrm{o}}$, and $\chi_{\mathrm{h}}$. The datapoints included in this figure are seasonally averaged values from each surface-layer CESM gridpoint for all four seasons. There is no strong relationship between $\chi_{\mathrm{a}}$ and $\chi_{\mathrm{o}}$, which shows that each mixing state index captures different aspects of the population mixing state. As mentioned above, a population can appear as completely internally mixed when we only consider "black carbon" and "other species" as the two surrogate species. At the same time, the distribution of model species can vary within the "other species" class, resulting in a comparatively externally mixed population $(<50 \%)$ in terms of $\chi_{\mathrm{a}}$. In contrast, a high value for $\chi_{\mathrm{a}}$ can correspond to a lower $\chi_{\mathrm{o}}$ in cases where the average particle species diversity $D_{\alpha}$ (in terms of optical properties) is low. This situation typically occurs when the particles are dominated by the "other species". A small fraction of "black carbon" exerts more influence on $\chi_{\mathrm{o}}$ than on $\chi_{\mathrm{a}}$. Similar principles apply to the relationship between $\chi_{\mathrm{h}}$ and $\chi_{\mathrm{a}}$, and $\chi_{\mathrm{h}}$ and $\chi_{\mathrm{o}}$.

Overall, these results illustrate that, when determining mixing state from observed data using a certain set of species (determined by the instrumentation), it is difficult to infer the mixing state based on a different set of species. Mixing state indices for different purposes capture different information about the aerosol. Therefore, care has to be taken regarding the comparison of mixing states in different environments when the measurement techniques to estimate particle mass fractions are different.

Figure 8 summarizes the averaged aerosol mixing indices in the Northern and Southern Hemispheres, and we conclude the following. (1) The mixing state indices during the winter were higher than during the summer. This seasonal difference was more pronounced for the Southern Hemisphere. (2) Overall, $\chi_{\mathrm{a}}$ and $\chi_{\mathrm{o}}$ were 13 and 12 percentage points higher than $\chi_{\mathrm{h}}$, respectively. (3) Regardless of which mixing state index we consider, extremely external mixtures ( $\chi$ lower than $20 \%$ ) were not predicted for the seasonal averages. We will investigate the variation of mixing state on shorter-than-seasonal time scales in a forthcoming paper.

\section{Conclusions}

In this paper, we presented a framework for estimating submicron aerosol mixing state indices at a global scale. A machine learning model (an emulator) was trained on high-detail simulations, using the particle-resolved PartMCMOSAIC, and then applied to the output from a coarser model (MAM4 within CESM) to enhance its information content.

We developed three emulators based on the XGBoost algorithm to determine the aerosol mixing state indices for sub-micron aerosol in terms of chemical species abundance $\left(\chi_{\mathrm{a}}\right)$, the mixing of optically absorbing and non-absorbing species $\left(\chi_{\mathrm{o}}\right)$, and the mixing of hygroscopic and non-hygroscopic species $\left(\chi_{\mathrm{h}}\right)$ using variables available in CESM. Based on error metrics for the testing dataset, the predictions of mixing state metrics have an error of approximately $\pm 10 \%$ associated with them, and somewhat higher for $\chi_{\mathrm{h}}$. The emulators were applied to CESM simulations to produce global maps of aerosol mixing state indices for every $3 \mathrm{~h}$ timestamp. For this work, we focused on seasonal variation and spatial distribution of these aerosol mixing state indices. 

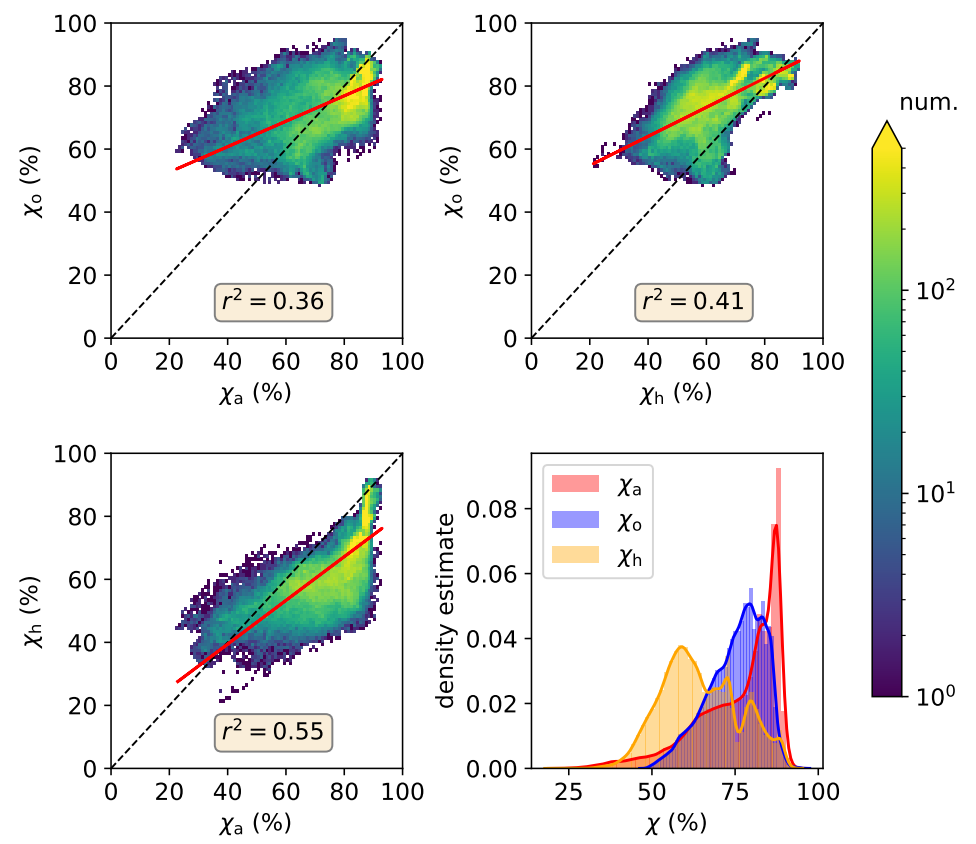

Figure 7: Relationship among aerosol mixing state indices $\chi_{\mathrm{a}}, \chi_{\mathrm{o}}$, and $\chi_{\mathrm{h}}$. Datapoints included here are seasonally averaged values from each surface-layer CESM gridpoint for all four seasons.
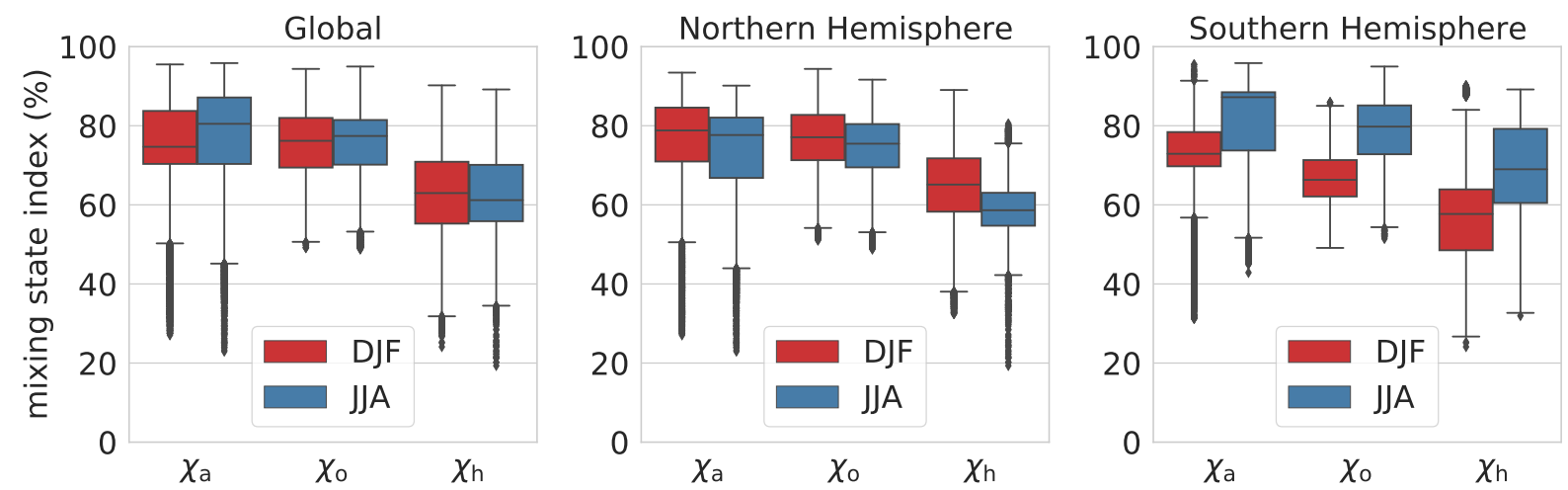

Figure 8: Aggregated statistics of aerosol mixing indices $\chi_{\mathrm{a}}, \chi_{\mathrm{o}}$, and $\chi_{\mathrm{h}}$ over the globe, in the Northern Hemisphere, and in the Southern Hemisphere in DJF and JJA. 
The indices ranged between $23 \%$ and $96 \%$ for $\chi_{\mathrm{a}}$, between $49 \%$ and $95 \%$ for $\chi_{\mathrm{o}}$, and $19 \%$ and $90 \%$ for $\chi_{\mathrm{h}}$, with averages of $76 \%, 75 \%$, and $63 \%$, respectively. Aerosol mixing state indices tended to be higher in the winter season, and this difference was more pronounced for the Southern Hemisphere.

High values in one mixing state index can be consistent with low values in another index, depending on the grouping of species and their relative abundance. This indicates that the different indices capture different aspects about the mixing state of an aerosol. When comparing mixing state indices for different environments from observations, care needs to be taken that they use the same choice of species as the basis.

Comparing our results with available ambient observations of mixing state indices in the literature is still challenging, as estimates of per-particle mass fractions needed to determine the mixing state indices are difficult to obtain and long-term records are not yet available. Qualitative comparisons with studies by Ye et al. [5] and Healy et al. [4] show that our results are similar in magnitude to the observations.

In a follow-up study, we will investigate temporal variation on shorter time scales (diurnal cycles). Furthermore, considering that MAM4 already represents mixing state to some extent, a comparison with the emulator predictions will be valuable.

\section{Data Availability}

Scripts and instruction to create the PartMC-MOSIAC scenarios are available at doi:10.5281/zenodo.3788110 or https://github.com/zzheng93/scenario_generator_james. Notebooks and data to reproduce the emulator development, emulator application, and global mixing state indices analysis are available at doi:10.5281/zenodo. 3788737 or https://github.com/zzheng93/code_global_ms_james. The temperature data from CESM CMIP6 output is available at/https://esgf-node.llnl.gov/search/cmip6/

\section{Acknowledgments}

We would like to acknowledge high-performance computing support from Cheyenne (doi:10.5065/D6RX99HX) provided by NCAR's Computational and Information Systems Laboratory, sponsored by the National Science Foundation. The CESM project is supported primarily by the National Science Foundation. This research used resources of the Oak Ridge Leadership Computing Facility, which is a DOE Office of Science User Facility supported under Contract DE-AC05-00OR22725. This research was supported in part by an appointment to the Oak Ridge National Laboratory ASTRO Program, sponsored by the U.S. Department of Energy and administered by the Oak Ridge Institute for Science and Education. We also acknowledge funding from DOE grant DE-SC0019192 and NSF grant AGS-1254428. This research is part of the Blue Waters sustained-petascale computing project, which is supported by the National Science Foundation (awards OCI-0725070 and ACI-1238993) the State of Illinois, and as of December, 2019, the National Geospatial-Intelligence Agency. Blue Waters is a joint effort of the University of Illinois at Urbana-Champaign and its National Center for Supercomputing Applications. Louisa Emmons is thanked for thoughful comments on the CESM2 simulations and the manuscript. We thank AWS for providing AWS Cloud Credits for Research.

\section{Supplementary}

The global distribution of sub-micron black carbon was in line with the global distribution of black carbon emission reported in past studies [51, 52, 53] with hotspots over eastern China, Indo-Gangetic plains in South Asia, most of Southeast Asia, regions of Africa between sub-Sahara and South Africa, Mexico and South America. The spatial distribution of the dust mixing ratio agreed with the study shown in [54, 55] where the hotspots occur in the bare desert and semi-desert regions. Notably, the Saharan dust dominated the Northern Hemisphere, and the Australian dust dominated the Southern Hemisphere. Because the sub-micron particles could be transported far inland with minor removal, we expect the mixing ratio of the sea salt was not zero over the land surface [56]. The global distribution of primary organic matter exhibited a similar pattern as the emission shown in Bond et al. [51], with hotspots in the same regions as the black carbon. Though, the simulated secondary organic aerosol concentration peaked over the southeast United States, South America, Central Africa, and southern Asia [58]. The global distribution of sulfate aerosol was in agreement with the global distribution of the annual mean of sulfate aerosol burden studied by Hommel el al. [57]. 

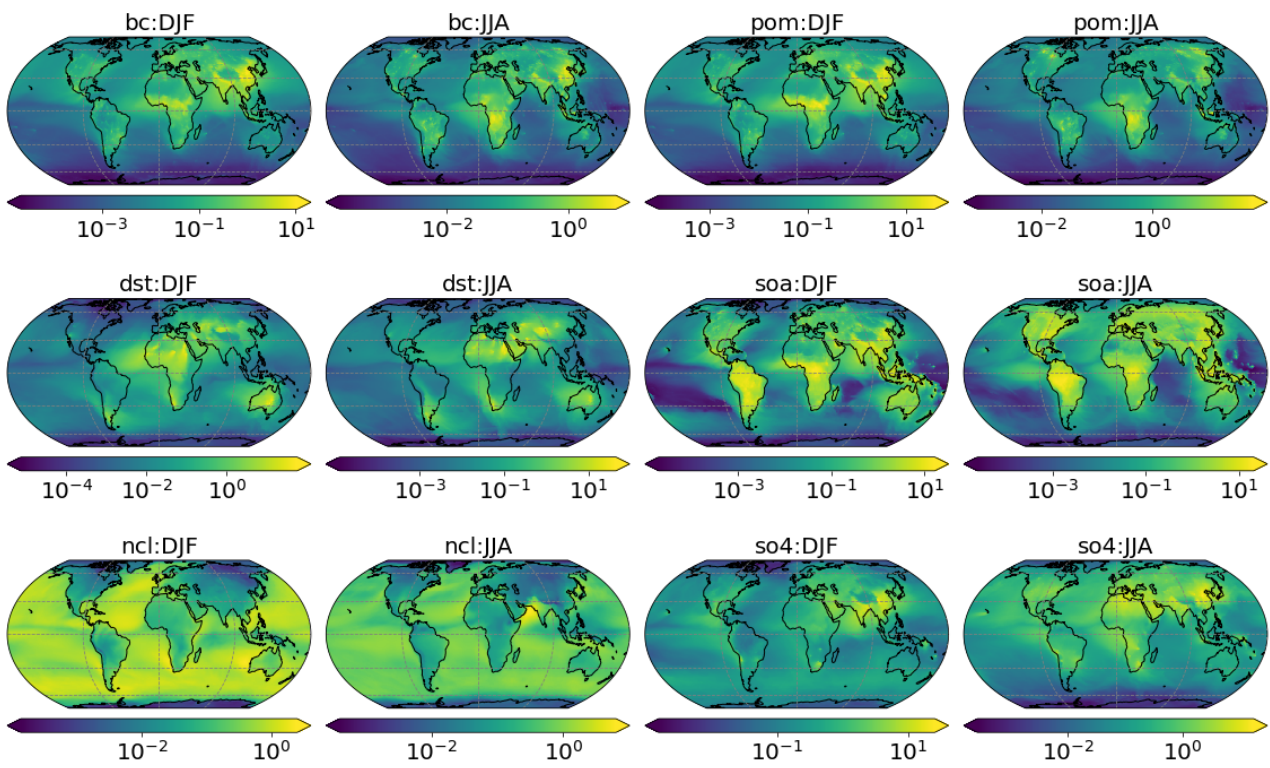

Figure S 1: Aerosol species mixing ratio $(\mu \mathrm{g} / \mathrm{kg})$.

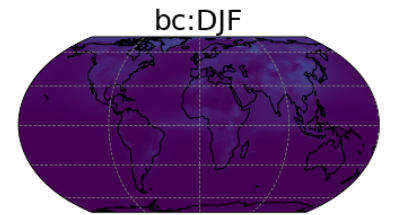

dst:DJF

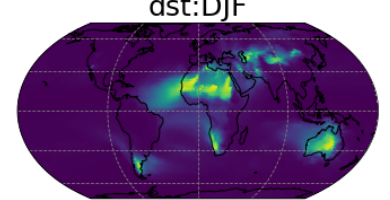

ncl:DJF
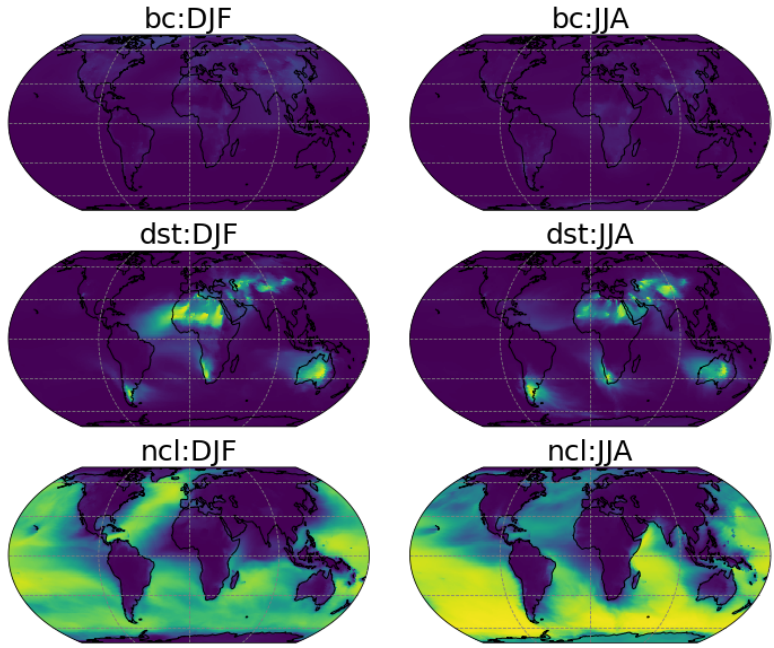

dst:JJA

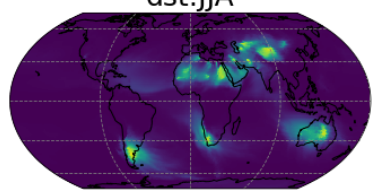

ncl:JJA

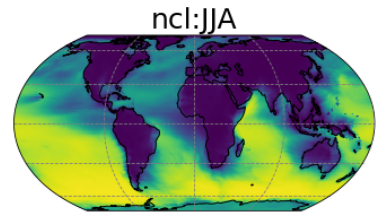

40

fraction of aerosol species mixing ratio (\%)

Figure S 2: Fraction of aerosol species mixing ratio (\%).
60

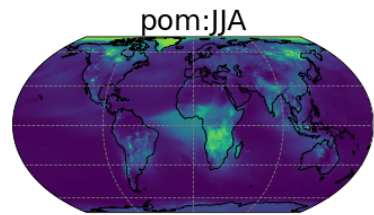

soa:JJA

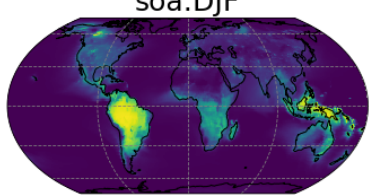

so4:DJF

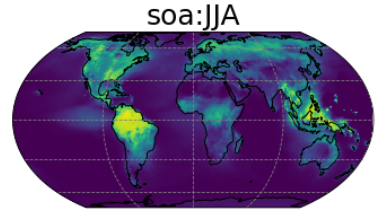

so4:JJA
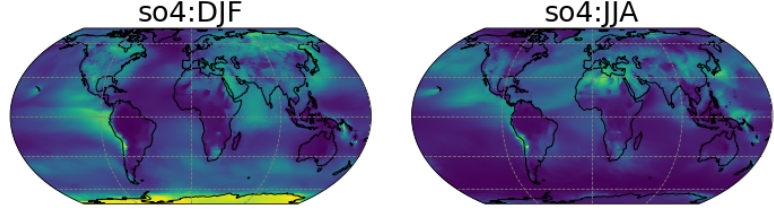

80 
A PREPRINT - MAY 5, 2020

\section{References}

[1] Riemer, N., Ault, A. P., West, M., Craig, R. L. \& Curtis, J. H. Aerosol Mixing State: Measurements, Modeling, and Impacts. Rev. Geophys. 57, 187-249 (2019).

[2] Winkler, P. The growth of atmospheric aerosol particles as a function of the relative humidity-II. An improved concept of mixed nuclei. J. Aerosol Sci. 4, 373-387 (1973).

[3] Bondy, A. L. et al. The diverse chemical mixing state of aerosol particles in the southeastern United States. Atmos. Chem. Phys. 18, 12595-12612 (2018).

[4] Healy, R. M. et al. Single particle diversity and mixing state measurements. Atmos. Chem. Phys. 14, 6289-6299 (2014).

[5] Ye, Q. et al. Spatial Variability of Sources and Mixing State of Atmospheric Particles in a Metropolitan Area. Environ. Sci. Technol. 52, 6807-6815 (2018).

[6] Yu, C. et al. Characterising mass-resolved mixing state of black carbon in Beijing using a morphology-independent measurement method. Atmos. Chem. Phys. 20, 3645-3661 (2020).

[7] Lee, A. K. et al. Influences of Primary Emission and Secondary Coating Formation on the Particle Diversity and Mixing State of Black Carbon Particles. Environ. Sci. Technol. 53, 9429-9438 (2019).

[8] Fierce, L., Riemer, N. \& Bond, T. C. Toward Reduced Representation of Mixing State for Simulating Aerosol Effects on Climate. Bull. Amer. Meteor. Soc. 98, 971-980 (2017).

[9] Holmgren, H. et al. Hygroscopic properties and mixing state of aerosol measured at the high-altitude site Puy de Dôme (1465 m a.s.1.), France. Atmos. Chem. Phys. 14, 9537-9554 (2014).

[10] Lesins, G., Chylek, P. \& Lohmann, U. A study of internal and external mixing scenarios and its effect on aerosol optical properties and direct radiative forcing. J. Geophys. Res. 107, AAC 5-1-AAC 5-12 (2002).

[11] Fierce, L., Bond, T. C., Bauer, S. E., Mena, F. \& Riemer, N. Black carbon absorption at the global scale is affected by particle-scale diversity in composition. Nat Commun. 7, 12361 (2016).

[12] Wang, J., Cubison, M. J., Aiken, A. C., Jimenez, J. L. \& Collins, D. R. The importance of aerosol mixing state and size-resolved composition on $\mathrm{CCN}$ concentration and the variation of the importance with atmospheric aging of aerosols. Atmos. Chem. Phys. 10, 7267-7283 (2010).

[13] Ching, J., Riemer, N. \& West, M. Impacts of black carbon mixing state on black carbon nucleation scavenging: Insights from a particle-resolved model. J. Geophys. Res. 117 (2012).

[14] Knopf, D. A., Alpert, P. A. \& Wang, B. The Role of Organic Aerosol in Atmospheric Ice Nucleation: A Review. ACS Earth Space Chem. 2, 168-202 (2018).

[15] Koch, D. et al. Evaluation of black carbon estimations in global aerosol models. Atmos. Chem. Phys. 9, 9001-9026 (2009).

[16] Riemer, N. \& West, M. Quantifying aerosol mixing state with entropy and diversity measures. Atmos. Chem. Phys. 13, 11423-11439 (2013).

[17] O’Brien, R. E. et al. Chemical imaging of ambient aerosol particles: Observational constraints on mixing state parameterization. J. Geophys. Res. 120, 9591-9605 (2015).

[18] Giorio, C. et al. Local and Regional Components of Aerosol in a Heavily Trafficked Street Canyon in Central London Derived from PMF and Cluster Analysis of Single-Particle ATOFMS Spectra. Environ. Sci. Technol. 49, 3330-3340 (2015).

[19] Ching, J., Fast, J., West, M. \& Riemer, N. Metrics to quantify the importance of mixing state for CCN activity. Atmos. Chem. Phys. 17, 7445-7458 (2017).

[20] Hughes, M., Kodros, J., Pierce, J., West, M. \& Riemer, N. Machine Learning to Predict the Global Distribution of Aerosol Mixing State Metrics. Atmosphere 9, 15 (2018).

[21] Hurrell, J. W. et al. The Community Earth System Model: A Framework for Collaborative Research. Bull. Amer. Meteor. Soc. 94, 1339-1360 (2013).

[22] Danabasoglu, G. et al. The Community Earth System Model Version 2 (CESM2). J. Adv. Model. Earth Syst. 12, e2019MS001916 (2020).

[23] Liu, X. et al. Description and evaluation of a new four-mode version of the Modal Aerosol Module (MAM4) within version 5.3 of the Community Atmosphere Model. Geosci. Model Dev. 9, 505-522 (2016). 
[24] Riemer, N., West, M., Zaveri, R. A. \& Easter, R. C. Simulating the evolution of soot mixing state with a particle-resolved aerosol model. J. Geophys. Res. 114, D09202 (2009).

[25] Zaveri, R. A., Easter, R. C., Fast, J. D. \& Peters, L. K. Model for Simulating Aerosol Interactions and Chemistry (MOSAIC). J. Geophys. Res. 113 (2008).

[26] Zaveri, R. A. \& Peters, L. K. A new lumped structure photochemical mechanism for large-scale applications. $J$. Geophys. Res. 104, 30387-30415 (1999).

[27] Zaveri, R. A., Easter, R. C. \& Wexler, A. S. A new method for multicomponent activity coefficients of electrolytes in aqueous atmospheric aerosols. J. Geophys. Res. 110 (2005).

[28] Zaveri, R. A., Easter, R. C. \& Peters, L. K. A computationally efficient Multicomponent Equilibrium Solver for Aerosols (MESA). J. Geophys. Res. 110 (2005).

[29] Schell, B., Ackermann, I. J., Hass, H., Binkowski, F. S. \& Ebel, A. Modeling the formation of secondary organic aerosol within a comprehensive air quality model system. J. Geophys. Res. 106, 28275-28293 (2001).

[30] Kaiser, J. C. et al. The MESSy aerosol submodel MADE3 (v2.0b): Description and a box model test. Geosci. Model Dev. 7, 1137-1157 (2014).

[31] Danabasoglu, G. NCAR CESM2 model output prepared for CMIP6 CMIP historical (2019).

[32] Omori, Y. et al. Sea-to-air flux of dimethyl sulfide in the South and North Pacific Ocean as measured by proton transfer reaction-mass spectrometry coupled with the gradient flux technique. J. Geophys. Res. 122, 7216-7231 (2017).

[33] Xu, L. et al. DMS role in ENSO cycle in the tropics. J. Geophys. Res. 121, 13,537-13,558 (2016).

[34] Lana, A. et al. An updated climatology of surface dimethlysulfide concentrations and emission fluxes in the global ocean. Global Biogeochem. Cycles 25 (2011).

[35] Wang, Y. H. et al. Aerosol physicochemical properties and implications for visibility during an intense haze episode during winter in Beijing. Atmos. Chem. Phys. 15, 3205-3215 (2015).

[36] Yu, F. \& Luo, G. Simulation of particle size distribution with a global aerosol model: Contribution of nucleation to aerosol and CCN number concentrations. Atmos. Chem. Phys. 9, 7691-7710 (2009).

[37] Asmi, A. et al. Number size distributions and seasonality of submicron particles in Europe 2008-2009. Atmos. Chem. Phys. 11, 5505-5538 (2011).

[38] Pierce, J. R., Croft, B., Kodros, J. K., D'Andrea, S. D. \& Martin, R. V. The importance of interstitial particle scavenging by cloud droplets in shaping the remote aerosol size distribution and global aerosol-climate effects. Atmos. Chem. Phys. 15, 6147-6158 (2015).

[39] Fraund, M. et al. Elemental Mixing State of Aerosol Particles Collected in Central Amazonia during GoAmazon2014/15. Atmosphere 8, 173 (2017).

[40] Dickau, M. et al. Methodology for quantifying the volatile mixing state of an aerosol. Aerosol Sci. Technol. 50, 759-772 (2016).

[41] Liu, X. et al. Toward a minimal representation of aerosols in climate models: Description and evaluation in the Community Atmosphere Model CAM5. Geosci. Model Dev. 5, 709-739 (2012).

[42] Chen, T. \& Guestrin, C. XGBoost: A Scalable Tree Boosting System. In Proceedings of the 22nd ACM SIGKDD International Conference on Knowledge Discovery and Data Mining - KDD '16, 785-794 (ACM Press, San Francisco, California, USA, 2016).

[43] Friedman, J. H. Greedy function approximation: A gradient boosting machine. Ann. Statist. 29, 1189-1232 (2001).

[44] Mott, A., Job, J., Vlimant, J.-R., Lidar, D. \& Spiropulu, M. Solving a Higgs optimization problem with quantum annealing for machine learning. Nature 550, 375-379 (2017).

[45] Abelson, S. et al. Prediction of acute myeloid leukaemia risk in healthy individuals. Nature 559, 400-404 (2018).

[46] Rosenberg, K. V. et al. Decline of the North American avifauna. Science 366, 120-124 (2019).

[47] Willmott, C. J. On the Validation of Models. Phys. Geogr. 2, 184-194 (1981).

[48] Bogenschutz, P. A. et al. The path to CAM6: Coupled simulations with CAM5.4 and CAM5.5. Geosci. Model Dev. 11, 235-255 (2018).

[49] Gantt, B., He, J., Zhang, X., Zhang, Y. \& Nenes, A. Incorporation of advanced aerosol activation treatments into CESM/CAM5: Model evaluation and impacts on aerosol indirect effects. Atmos. Chem. Phys. 14, 7485-7497 (2014). 
[50] He, J. \& Zhang, Y. Improvement and further development in CESM/CAM5: Gas-phase chemistry and inorganic aerosol treatments. Atmos. Chem. Phys. 14, 9171-9200 (2014).

[51] Bond, T. C. et al. A technology-based global inventory of black and organic carbon emissions from combustion. $J$. Geophys. Res. 109 (2004).

[52] Ramanathan, V. \& Carmichael, G. Global and regional climate changes due to black carbon. Nature Geosci 1, 221-227 (2008).

[53] Bond, T. C. et al. Bounding the role of black carbon in the climate system: A scientific assessment. J. Geophys. Res. 118, 5380-5552 (2013).

[54] Mahowald, N. M. et al. Atmospheric global dust cycle and iron inputs to the ocean. Global Biogeochem. Cycles 19 (2005).

[55] Tanaka, T. Y. \& Chiba, M. A numerical study of the contributions of dust source regions to the global dust budget. Glob. Planet. Change 52, 88-104 (2006).

[56] Sofiev, M., Soares, J., Prank, M., de Leeuw, G. \& Kukkonen, J. A regional-to-global model of emission and transport of sea salt particles in the atmosphere. J. Geophys. Res. 116 (2011).

[57] Hommel, R., Timmreck, C. \& Graf, H. F. The global middle-atmosphere aerosol model MAECHAM5-SAM2: Comparison with satellite and in-situ observations. Geosci. Model Dev. 4, 809-834 (2011).

[58] Lack, D. A., Tie, X. X., Bofinger, N. D., Wiegand, A. N. \& Madronich, S. Seasonal variability of secondary organic aerosol: A global modeling study. J. Geophys. Res. 109 (2004).

[59] Raatikainen, T. et al. Black carbon concentrations and mixing state in the Finnish Arctic. Atmos. Chem. Phys. 15, 10057-10070 (2015).

[60] Oshima, N., Koike, M., Zhang, Y. \& Kondo, Y. Aging of black carbon in outflow from anthropogenic sources using a mixing state resolved model: 2 . Aerosol optical properties and cloud condensation nuclei activities. $J$. Geophys. Res. 114 (2009). 